\title{
Girls Bullying in Nepali Schools: A Perception Study on Awareness Level of Verbal and Non-verbal Bullying Among Teenagers
}

\author{
Megh R. Dangal \& Aishwarya R. Singh \\ Kathmandu University, School of Arts, NEPAL
}

Received: 28 December 2019 • Accepted: 5 March 2020 • Published Online: 13 March 2020

\begin{abstract}
This article deals with the issue related to bullying and addresses the awareness level of girls bullying practices in school. Schools are expected to be safe for children considering that they spend maximum hours in that very environment. However, school bullying has threatened children's security in the school. Often understood as the phenomenon of repeatedly being exposed to negative action imposed by peers. School bullying impacts the overall physical, mental and emotional health of a student and also their academic performance and social relationships. This affects their entire life and learning process. Immediate attention is required to make both the school and parents aware of the phenomenon of school bullying and the detrimental impact it has on children in order to ensure a secure learning space in the school.
\end{abstract}

Keywords: school bullying, awareness, perception and practices, mental and physical health, prevention.

\section{Introduction}

School is a place that provides a secure and safe environment for youths to learn as students spend a considerable amount of time in school (Smith \& Shu,2000). However, students have started to regularly experience the phenomenon of school bullying (Gruber \& Fineran, 2007) and have started to fall prey of school bullying by their peers (Arseneault et al., 2010). This is greatly threatening their security in the school. Olweus (1994) defines bullying as a hurtful action between peers due to power imbalance which occurs due to the difference in age, status, physical strength and popularity in school. This power balance often leads to peers demonstrating repeated hurtful actions.

Research has shown that both the boys and girls can either be the bully or the victim of school bullying. However, boys are found being engaged in direct bullying contrary to girls who are found to be engaged more in indirect bullying (Bjorkqvist et al., 1992). Bullying has been identified mainly in two forms. One is direct bullying which includes verbal and physical behavior like threatening and beating, and indirect bullying which includes spreading rumors and group exclusion (Olweus, 1993a). Bullying can also take place in the school in the form of sexual harassment like passing sexual comments (Nansel et al., 2001).

Both girls and boys are subjected to being bullied, however, girls experience more negative behavior from their peers resulting in more negative output (Lee et al., 1996, Molidor \&

(C) Authors. Terms and conditions of Creative Commons Attribution 4.0 International (CC BY 4.0) apply. Correspondence: Megh R. Dangal, Kathmandu University, School of Arts, Kathmandu, NEPAL. E-mail: megh@ku.edu.np. 
Tolman, 1998). Girls deal with problems such as group conformity, emphasis on beauty, dating, and experience bullying more often because of their appearance and peer group status (Gruber \& Fineran, 2007). Hawker and Boultan (2000) discover that bullied girls are 8 times more likely to commit suicide compared to bullied boys who are 4 times more likely.

As bullying has a detrimental impact on students long-term emotional, mental, physical health, academic performance and the social relationship it is crucial for this issue to be brought into the concern of stakeholders-school, family and society as a whole. This article thus aims to identify the status of the awareness level on school bullying and its effect on teenagers and thereby underscore the threat imposed by it while also suggesting measures to tackle school bullying in the school and the ways through which victims can be supported.

On this regard, this article is divided into two halves. The first half aims at finding the awareness status of bullying on girl students. A convenience sampling method was used under a non-probability quantitative sampling method. The cases that were accessible to the researcher as per the convenience were selected (Yegidis \& Weinbach, 1996). Through a questionnaire survey, 30 female students were approached and the questionnaire survey had been conducted.

The second half of the article identifies the perceptions of school bullying on girl students. For this, the study has adopted the qualitative study method. The school bullying victim student has been purposively selected from among the pool of the same 30 female students who participated in the questionnaire survey. The female student then was interviewed through an indepth interview. A checklist was prepared to conduct the in-depth interview. The research participant had been approached more than once to build a rapport and make her feel comfortable to speak.

This article, however, has its own limitation. The article doesn't include all the girl school bullying victim. It besieges the finding derived out of only two girl school bullying victims (taken as a case study). However, it gives an overview of school bullying and the various effects it has on an individual.

\section{Awareness on school bullying}

To identify the awareness level on bullying the questionnaire were developed focusing on the types of bullying given by Rana (2006) which has been presented below in the table.

Table1. Different types of bullying (Rana, 2006)

\begin{tabular}{lll}
\hline & Direct & Indirect \\
\hline Physical & Hitting & Getting others to assault \\
& Kicking & \\
Spitting & \\
Throwing Objects & Spreading malicious rumors \\
Verbal & Name calling & \\
Threatening & Gestures & Stealing/ hiding belongings \\
Non-verbal & & Sending vicious notes \\
& & $\begin{array}{l}\text { Deliberately excluding from a } \\
\text { group } \\
\text { Cyber-bullying }\end{array}$ \\
& & \\
\hline
\end{tabular}


The result of the questionnaire survey done with the 30 girl students in order to be able to identify the states of the awareness level on school bullying has been presented in the upcoming sections.

\subsection{Understanding of school bullying}

The general understanding of the participants about school bullying has been depicted in the given figure 1 and 2. Figure 1 depicts that among the total 30 participants, 50\% of the participants claimed that they knew what school bullying is and the rest $50 \%$ did not know. Figure 2 depicts that among the 50\% (15 of the participants who claimed that they knew what school bullying is), 15 of the total participants associated school bullying with ragging and physical torture, 11 associated it with verbal abuse and only 2 associated it correctly with both physical, emotional and mental torture. The rest 15 were the ones who claimed that they didn't know what school bullying meant. The participants choose more than one option, thus the number exceeds more than 30 in the figure given below.

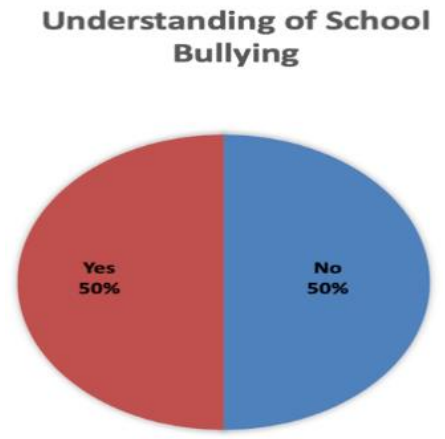

Figure 1: Understanding level on school bullying

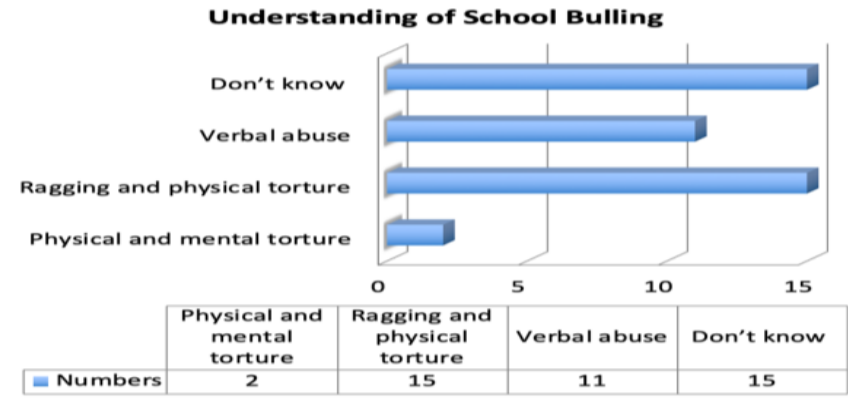

Figure 2: Understanding level on school bullying

\subsection{Effects of school bullying}

The effects of school bullying given by the participants have been shown in figure 3 . The figure demonstrates that among the total 30 participants 12 participants claimed that school bullying has effect on mental health (causes depression and anxiety), 13 claimed that the victims of school bullying have poor school performance, 6 claimed that victims become lonely, 3 claimed that victims have poor physical health and the rest 15 claimed that they didn't know the answer. The participants choose more than one option, thus the number exceeds more than 30 in the given figure.

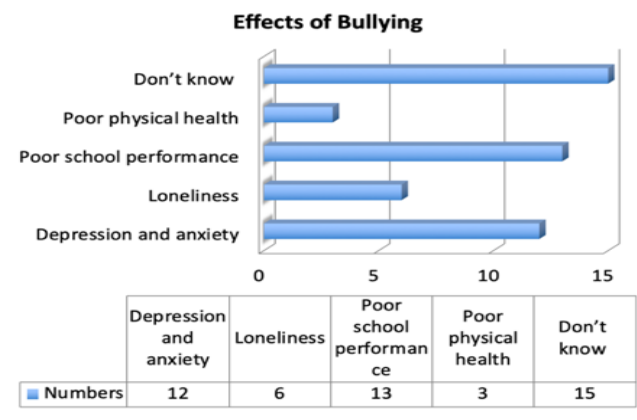

Figure 3: Effects of school bullying 


\subsection{Awareness level on physical bullying}

The awareness level on physical bullying and the ways of physical bullying has been shown in figure 4 and 5 respectively. Figure 4 demonstrates that among the total 30 participants, $50 \%$ were both aware and unaware of what physical bullying actually was.

Out of the total $50 \%$ participants who were aware of the physical bullying, $67 \%$ and $33 \%$ among them responded that hitting and kicking was physical bullying respectively. The figure 5 clearly depicts that even among the participants who were aware of physical bullying, considered only hitting and kicking as part of it and were unknown about other forms such as spitting, throwing objects and getting others to assault (Rana, 2006).

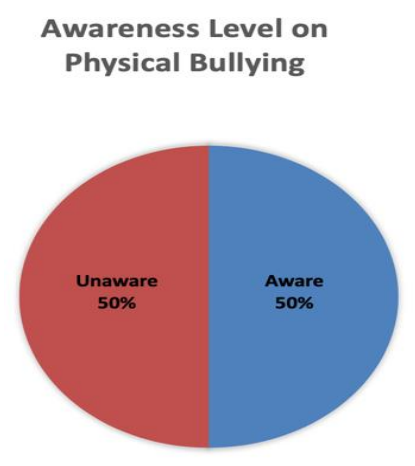

Figure 4: Awareness level on physical bullying

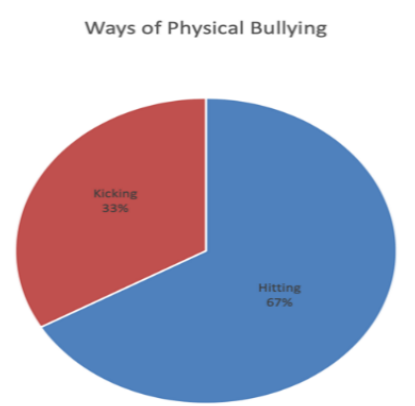

Figure 5: Ways of physical bullying

Figure 6, shows that out of the total $50 \%$ participants (15 of participants) who claimed that they were aware of physical bullying, 8 of them have been physically bullied (by being thrown with stationaries in the class), 5 have witnessed it and 1 each have stood up against it and physically bullied others.

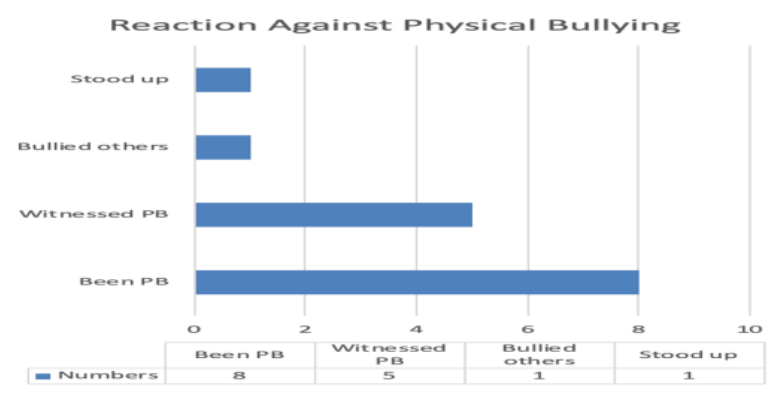

Figure 6: Reaction against physical bullying

\subsection{Awareness level on verbal bullying}

The awareness level on verbal bullying and ways of verbal bullying has been shown in figure 7 and 8 respectively. Figure 7 demonstrates that among the total 30 respondents $63 \%$ and $37 \%$ were unaware and aware respectively of verbal bullying.

Out of the total $37 \%$ participants who were aware of verbal bullying, $79 \%, 16 \%$, and $5 \%$ responded that insulting, name-calling and threatening respectively were ways of verbal bullying, as has been shown in figure 8 . 
Awareness Level on Verbal

Bullying

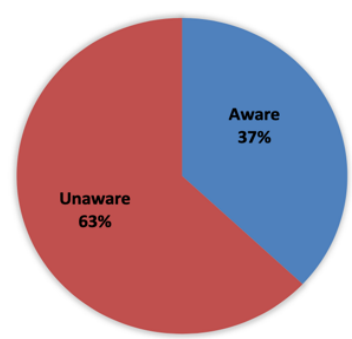

Figure 7: Awareness level on verbal bullying

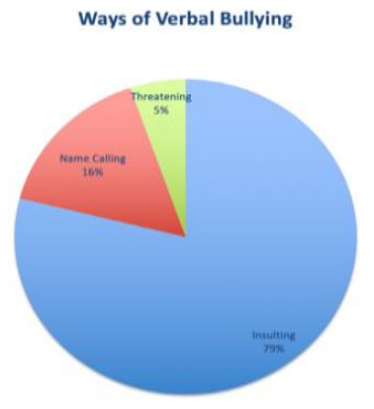

Figure 8: Ways of verbal bullying

Figure 9, shows that out of the total $37 \%$ participants (11 of the total participants) who were aware of verbal bullying, 14 of them have witnessed it,10 of them have been verbally bullied, 7 of them have stood up against it and 5 of them have verbally bullied others. The participants choose more than one option, thus the number of respondents exceeds more than 11 in the figure given below.

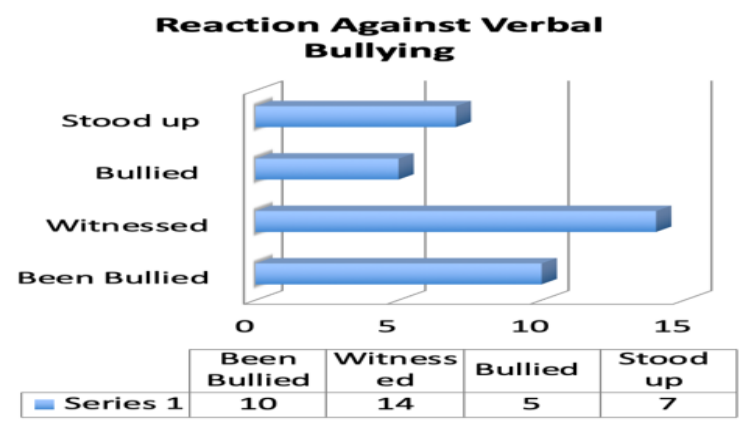

Figure 9: Reaction against verbal bullying

\subsection{Awareness level on non-verbal bullying}

The awareness level on non-verbal bullying and ways of non-verbal bullying has been shown in figure 10 and 11 respectively. Figure 10 demonstrates that among the total 30 participants, 93\% and 7\% were unaware and aware respectively about what non-verbal bullying was.

Figure 11 depicts that out of the total $7 \%$ participants who were aware of the non-verbal bullying, each 50\% among them responded that cyberbullying and negative gestures (eye rolling and staring) were an indication of non-verbal bullying.

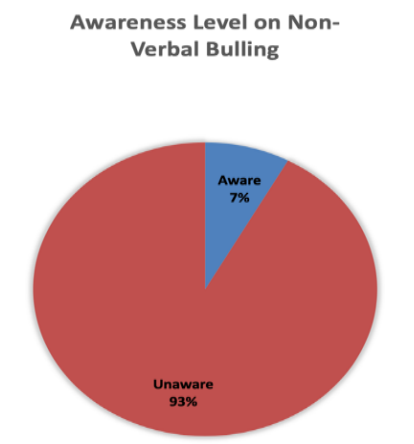

Figure 10: Awareness level on non-verbal bullying

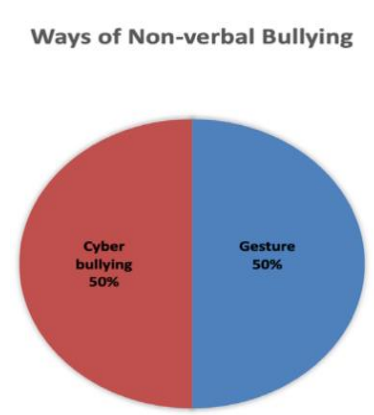

Figure 11: Ways of non-verbal bullying 
Figure 12, shows that out of the total $7 \%$ participants ( 2 of the total participants) who were aware of non-verbal bullying, all $7 \%$ of the participants have been non-verbally bullied.

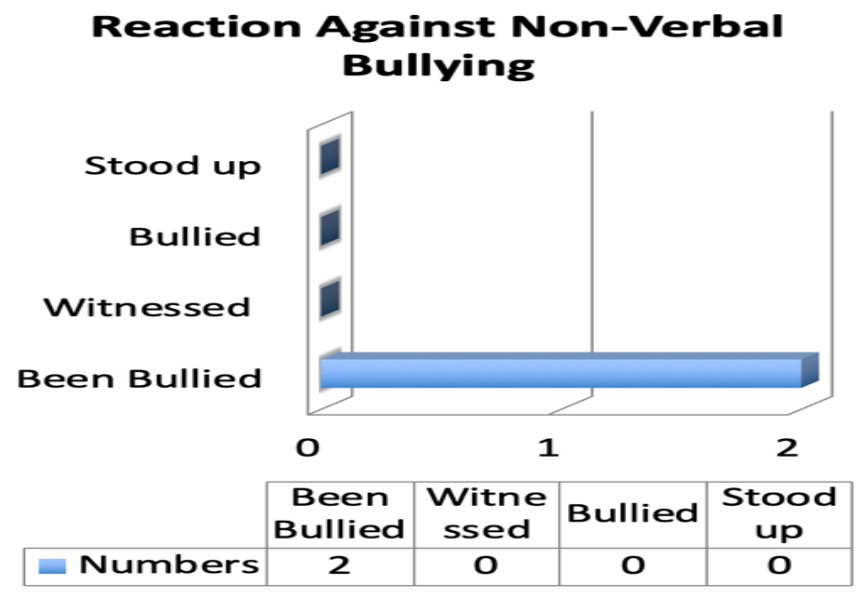

Figure 9: Reaction against non-verbal bullying

3. Perceptions and practices of school bullying

\subsection{Overview of school bullying}

Widely viewed as a major problem in several countries, Smith and Sharp (1994), define school bullying as an abuse of power. In order to further elaborate the meaning of school bullying, Olweus (1994) states that the repeated exposure of victims to the negative actions over time creates difficulty to him/ her for defending oneself from bullying. School bullying has been often characterized by intentionality, repetition and imbalance and abuse of the power (Olewus,1997; Smith \& Morita, 1999; Vaillancourt, Hymel, \& Mc- Dougall, 2003).

Elaborating furthermore on the definition of bullying, Dake et al. (2003) state, "A student is being bullied or victimized when he or she is exposed, repeatedly and over time, to negative actions on the part of one or more students." Dake et al. (2003) find the following features of bullying:

- Needs of imbalance in power between the people (or person) harassing and the person being harassed.

- The behavior demonstrated in a negative action which is intended at hurting the person being victimized.

- Bullying is a repeated action.

- Bullying is aggressive behavior.

- The act of bullying has severe consequences on the victimized person.

Madhvi, 18 (name changed), states: "I was bullied every single day throughout my grade 10. The behavior of my friends towards me was horrible. I was completely alone. It was torture to go to school every day and I could not do anything about it." Taking her incident into account, it can be understood that the school bullying victims go through negative behavior repeatedly and are forced to live with it. Considering that school bullying victims deal with the situation all by themselves, they feel powerless to do anything about the situation. 


\subsection{Reason for being bullied}

Madhvi (18), mentions: "For a long time I have felt that I was the reason myself for being the victim of bullying as I felt I was ugly and insufficient. Throughout, my childhood my parents were never around me and growing up I continuously felt that I was unloved and hated by everyone." Through the eyes of the victim, she considers her own inadequacy to be the main reason for her to be bullied. This led to her developing an inferior complex, thus, constantly blaming herself for being responsible for the bullying. This trait can be related to Sullivan et al. (2004) who mentions that the victim often thinks that because they are inadequate, they are responsible for the bullying.

In a more general vision, the reason of being different or odd from the group has been identified for the results in increased bullying to a victim (Frisén, Holmqvist \& Oscars-son, 2008; Frisén, Jonsson \& Persson, 2007; Hamarus \& Kaikkonen, 2008; Thornberg, 2010; Varjas et al., 2008). The intolerance to the difference and oddness of an individual from an entire group (Cadigan, 2002; McDonald \& Swart, 2004) results in the greater action of excluding and treating the individual in an entirely different manner often with more hostility. This differentness is mainly in terms of being less physically attractive, overweight, having a disability or performing poorly at school (Sweeting \& West, 2001).

Madhavi (18) mentions: "I was a shy and introvert child during my early primary school days and I feel this is the reason why I was repeatedly bullied by my friends. I felt I was ugly and not loved by anyone. Therefore, I could never connect with anyone and had social anxiety. When I started to become active and participate in extra-curricular activities. After reaching grade 7, I started becoming recognized in school and was a popular kid. However, due to jealousy, my friends started bullying me again. I did not have a single friend who supported me."

Taking her case into consideration it can be understood that differentness and being unable to fit in a group like Sweeting and West (2001), state leads to bullying. The differentness can be in terms of being both shy and introvert or being active and extrovert. Either of the situations leads to school bullying as the victim is conditioned to be "odd" one out in the group.

The significant impact of school bullying has raised many concerns towards the reason behind bullying. Individuals personal character and preference have also found to be a contributing factor in making the person prone to school bullying. One of the contributing factors is an individual's behavior like being introvert, shy and preferring to be alone. These are often considered the sign of weakness by the bullies. In this regard, it is important for the bully to always feel superior and strong in front of the peer whom they have targeted and recognized as weak.

Weiss (1973) mentions the two dimensions of loneliness. Social loneliness is related to lack of social network and emotional loneliness is related to lack of close friendship. Social loneliness is often the result of social anxiety. Social anxiety has been defined as the fear and apprehension a person experiences when they anticipate being unable to leave a positive impression on another person (La Greca \& Lopez, 1998). Socially anxious person eschews from social interaction and develops low self-esteem (Crick \& Bigbee, 1998). Students showing antisocial behavior in early childhood days are more prone to facing adversities related to bullying (Moffitt et al., 2002b).

Social loneliness and lack of close friends leads to an increase in the chances of being bullied and victimized. Bullies are often found targeting individuals who isolate themselves from the group interaction and lack understanding and caring peers. In this scenario, the individual is found defenseless against it (Emmanuel et al., 2016). The above cases of being socially anxious, shy and introvert and lacking close friends have been apparent in Madhvi's case too, thus leading to furthermore bullying experience. 


\subsection{Practices of school bullying}

Bullying has been identified mainly in two forms. One is direct bullying which is open attacks on a victim (Boulton et al., 2002) that are carried out face to face (Lee, 2004). It mainly includes verbal and physical behavior like threatening, beating and name-calling. Indirect bullying is more subtle and indirect (Boulton et al., 2002). It includes spreading rumors and group exclusion (Olweus,1993b). Due to technological advancement, the physical form of bullying has declined to some extent, however, the rise of other forms of bullying such as cyberbullying have been observed which has increased victimizations in the present scenario. been listed below.

Lee (2004) has also described three major sub-types of bullying behavior which has

\subsubsection{Physical bullying}

Table 2. Indirect form of physical bullying

\begin{tabular}{lll}
\hline Extortion - where threat of & $\begin{array}{l}\text { Threat of violence or gestures } \\
\text { and body language which is }\end{array}$ & Making faces and dirty \\
violence leads the victim to & gestures. \\
give up money or possessions. & intimidating. &
\end{tabular}

Glover, Gough, Johnson and Cartwright (2000) have given the following physical bullying activities (Table 3).

Table 3. Physical bullying activities

\begin{tabular}{ll}
\hline Physical Bullying & Damage to property \\
\hline Threatened with violence & Food taken \\
Pushed & Schoolbag taken \\
Pulled by the hair & Property damage \\
Slapped & School books damaged \\
Punched & Clothes taken or damaged \\
Kicked and Tripped & Money demanded \\
Stamped on or Spat on & Made to fight \\
\hline
\end{tabular}

\subsubsection{Verbal bullying}

Lee (2004), Boulton et al. (2002) and Coloroso (2003) have mentioned the following types of verbal bullying (Table 4).

Table 4. Types of verbal bullying

\begin{tabular}{ll}
\hline Name-Calling & Offensive, threatening and insulting remarks \\
\hline Threatening the victim & Taunting \\
Teasing & Belittling \\
Cruel criticism & Personal defamation \\
Racist slurs & Sexually suggestive or sexually abusive \\
& remarks. \\
\hline
\end{tabular}




\subsubsection{Social bullying}

Lee (2004) defines social bullying as intended group exclusion. Coloroso (2003) claims that it is difficult to identify social bullying from the outside. It can be direct often demonstrated with an exclusion, ignoring, isolating, or shunning experienced by the victims. Indirect forms include exclusion carried out without victims notice and is not experienced by them until they are told of it or they attempt to join the group (Lee, 2004; Coloroso, 2003).

Coloroso (2003) and O’Moore and Minton (2004) have listed the following activities as social bullying (Table 5).

Table 5. Social Bullying Activities

\begin{tabular}{lll}
\hline Aggressive stares & Frowns & Hostile Body Language \\
\hline Rolling of eyes & Sneers & Shaking Fists \\
Sighs & Snickers & Looks or glances that contain nasty messages \\
\hline
\end{tabular}

\section{Experience of bullying}

Madhvi (18) shares: "My classmates treated me like a walking parasite. I was always excluded from the group and had no friends. They spread a rumor about me that I was a prostitute. People used to draw a filthy sketch of me and pass it in the classroom. I knew I was bullied because I had to go through the same actions every day."

Madhvi's case demonstrates that she was victimized through verbal bullying in terms of name calling and belittling. As part of social bullying, she had to also confront social exclusion and troublesome gestures (eyes rolling, body language suggestive of exclusion from group and backbiting). She was the victim of both direct and indirect bullying.

Madhvi's bullying experiences are rooted in indirect bullying initiated with the spreading of rumors that lead to name-calling, group exclusion, isolation and unacceptable troublesome body gestures. Taking Madhvi's case into account it can be concluded that a person can be the victim of various types of bullying at the same time. Direct and indirect bullying can both occur at the same time with one particular type reinforcing the another and exposing the victims repeatedly to negative actions.

Madhvi (18) also shares: "I was bullied by my own best friend. She was someone I was very close with and I felt that she truly cared for me. It was only later that I discovered that she pretended to befriend me and was the one to start the rumors and spread it to other friends and juniors in my school."

In Madhvi's case, her own friend ended up being her bully. This bully depicts the character of a social bully, who according to (Coloroso, 2003), bully the victim by spreading a rumor, verbal taunts and isolate the target by excluding them from social activities. Also, the social bully is jealous of the victim's positive qualities and holds a poor sense of self, concealed by overstated confidence and charm. The bully may act caring in the beginning but is often manipulative. Through the rumors that had been made and spread throughout the school, Madhvi also became the target of the "bunch of bullies", where her own group friends, after being manipulated by the social bully and listening to the rumors started behaving negatively towards her.

\section{Effects of school bullying}

School bullying can emotionally destroy a person and should not be considered as a normal part of growing up (Anderson, 2007). "All research on the effects of bullying shows how 
damaging and destructive it is" (Sullivan et al., 2004). Garrett (2003) mentions that victims carry the scars forever despite surviving the bullying. Madhvi's case was very similar to what Garett (2003) states. She shared: "Sometimes I wake up in the middle of the night, drenched in sweat from the thought of going through the experience again. Despite being done with school and being in high school, I feel like I still have to go to school the next morning and that the bullying never really stopped. My body turns cold when I dream about the friends I had and wake up with happy thoughts until I realize what they've done to me. It haunts me so much that it feels like it never ended." Despite experiencing bullying two years back, Madhvi has been dealing with the impact of it till date. It won't be wrong to state that bullying can affect an individual for a lifetime the way it has affected Madhvi.

Madhvi (18) shared: "Ever since the bullying started, I have been diagnosed with medical depression and anxiety. The fear and pain have never left me. I have felt suicidal many times and have hurt myself [showing the scars in her arms]. Ever since class 10 both my physical and mental health has been deteriorating. I feel weak and tired all the time. I feel lethargic and I am sleeping most of the time." Madhvi's case highly relates to the conclusion made by number of researches who state that children who are victim of school bullying show signs of mental health issues like anxiety and depression (Hawker \& Boultan, 2000; Bond et al., 2001), have issues internalizing problems (harmful to oneself) (Hodges \& Perry, 1999; Arseneault et al., 2006) and externalizing problem (harmful behavior to others, aggression) (Nansel et al., 2001). Researches have also discovered the high risk of depression between the age of 31 and 51 years for those individuals who have been bullied in childhood (Lund et al., 2009). 28\% of psychiatric disorders between the ages of 18 and 23 years has been related to being regularly bullied in school days (Sourander et al., 2007a). High level of insecurity, loneliness, low self-esteem, and ebbing mental and physical symptoms are also associated with school bullying (Gruber \& Fineran, 2007). School bullying thus impacts the overall health and wellbeing of a student ranging from emotional, physical and mental well-being.

Adding on Madhvi (18) also shared: "My childhood was terrible as my parents were never around to love me. The same environment prevailed in the school as there were no friends to support me." Taking this case into account it can be stated that the impact of bullying is evident through worry, sadness, and nightmares and can lead to long-term adjustment problems in victims too. Furthermore, the effect of school bullying has also been related to sexual development and maturity of an individual. Hutchinson (1999) has claimed that at the age of 11-20, a person experiences biological, psychological and social change. Bullying experience by a student during the first adolescent phase have different experience later. The different experience can be in form of mental health problem which can be rooted in the childhood experience (Kim-Cohen et al., 2003) or misinterpreting the environment they are in and often tending to be very pessimistic (Kinderman \& Bentall, 1996). The impact is rather a long-term leading to deteriorating health issue during adolescence (Arseneault et al., 2010). This was clearly apparent in Madhvi's case too where the experience of school bullying had made her feel vulnerable with ebbing mental health and negative outlook towards life.

Apart from affecting an individual's well-being, school bullying is found affecting the social relationship of victim-students too. National Institute of Child Health and Human Development (1998) find out that bullied victims have difficulty making friends and have a poorer relationship which leads to loneliness and further deterioration in their mental health. This case is similar to Madhvi's too who claimed: "I prefer being alone as I am fearful that I will always be bullied and tortured. I feel too vulnerable and afraid to make friends."

The effect of school bullying is not just seen in the wellbeing of students but it also ends up affecting their growth and performances. School absenteeism and drop out in school years have also been characterized under the indicators of victimization by Hazler, Hoover and Oliver (1992), and Kochenderfer and Ladd (1996). This was evident in Madhvi's case too. She claimed: "I 
rather felt like dying than having to go to school as I knew I would be tortured again. I used to look for excuses to not go to school. I preferred sleeping for the entire day than attending the classes. I used to be absent a lot and this affected my grades and overall academic performances."

Taking into consideration Madhvi's overall experience of school bullying, it can be stated that school bullying affects all the spheres of an individual life ranging from personal, mental and physical health to social relationships and also academics.

\section{Preventing school bullying}

Researches have shown that the susceptibility of school bullying is greater in a peer group with lower adult supervision (Vaillancourt et al., 2010). In case of parents, the bullying to their children is an unknown while, on the other hand, the bullying may not be witnessed (Cornell \& Brockenbrough, 2004) or may be ignored by the teachers (Craig, Pepler \& Atlas, 2000).

\section{Case Study}

My name is Richa, 19 (name changed) and did my schooling from SX school (name changed). I had to repeat grade one. Prior to studying in SX school, I studied in SZ school (name changed). I still shiver whenever I remember the days I used to get bullied back in the previous school. I was bullied since grade L.K.G. I had a friend named Ruchi (name changed). She used to always isolate me from the group and manipulate my friends to stay away from me. She used to steal my stationeries and damage my copies and books by tearing it. Moreover, she used to demand things from me to be her friend. Every day I had to offer or something to be involved in the group. I used to be a little tomboyish when I was small. Ruchi used to tease me through name-calling and embarrass me in front of the entire class.

One day my sister discovered that her possessions were missing while cleaning her room. She told my mother about this and they started investigating. Ultimately, they found out that it was me as I stood shivering in silence. My mother scolded me and slapped me too. She also mentioned how my stationeries had been missing since long and how occasionally I used to demand money from her.

Upon frequently enquiring about my sister's lost possessions what I used to spend money on, I revealed the truth to her. I had no other choice left except to reveal the truth. But this I could do only after enduring the torture for three consecutive years.

My mother couldn't resist the fact that I had to go through painful situations every day in school. Understanding my situation, she started feeling sympathetic towards me and also asked my sister to forgive me. The very next day she went to the school and put forward her concern to the school management. The teachers took the issue very lightly and there was no end point to the bullying. Ultimately, my mother decided to change my school as she saw it to be the only option and solution left.

form

*note the participant chose to share her school bullying experience in the written

Madhvi's (18) experience shows similar aforementioned features. She shares: "My teachers always felt that I was the notorious kid because I could never do well in my studies. I was always hesitant to share my problem with them because I knew they would not take me seriously. I did complain to my school principal about being bullied, however, she asked me to be strong and ignore what others had to tell. I reached out to my parents too but they felt I was doing well and never took me seriously."

In relation to what Madhvi and Richa had to share about always being left helpless in the bullying situation, the number of crucial factors needs to be brought into serious consideration to prevent school bullying. Peer acceptance and a strong network of friendship has proved to become important during school days for wellbeing (Prienstien et al., 2001) as they serve as a protective factor against peer victimization (Hodges \& Perry, 1999). It can be strongly argued that 
building a strong network of friendship is not a skill a bullied victim holds however; an effort can be directed into teaching social skills and network building skills to the students. The sense of strength and power is often perceived by students in terms of being outspoken, expressive and having many friends can prevent bullying to a large extent.

Parental support and positive parenting are also important to assure the social and emotional wellbeing of a student (Kim-Cohen et al., 2003). Parents should always provide a friendly environment for students to be able to share their feelings and thoughts. Through open communication, parents can get a hint of their children being school bullying victims.

Apart from friends and parents being supportive, the school administration needs to play a crucial role in paying attention to the school bullying (Gruber \& Fineran, 2007). School bullying takes place within the confined boundary of school, thus it's of a pivotal necessity for the teachers and school staffs to be extra attentive towards their students and be watchful of the activity's students are indulged into during the school hours both inside and outside the classroom.

\section{Conclusion}

The research finding clearly depicts that school bullying is a major issue threatening the young lives and creating long term detrimental impacts on the students physical and mental health. The repeated exposure to the negative situation leads to hampering the victim's daily lifestyle and overall performance.

Controlling and preventing school bullying requires both schools and parents to take serious actions and precautionary measures to ensure that school becomes a safe place for students to learn and grow and not a place where their entire life gets affected. Spreading awareness, ensuring strict rules and regulations, supporting the students and having an open and friendly conversation with them are some of the measures that can be immediately implemented.

\section{Acknowledgements}

This research did not receive any specific grant from funding agencies in the public commercial, or not-for-profit sectors.

The authors declare no competing interests.

\section{References}

Anderson, G. (2007). The impact of bullying in school on the adolescent's sense of self. Masters Dissertation, University of Pretoria, South Africa.

Arsenautl, L., Bowes, L., \& Shakoor, S. (2010). Bullying victimization in youths and mental health problems: "Much ado about nothing?". Retrieved from https://www.researchgate.net/publication/26852871 Bullying victimization in youths an d mental health_problems_'Much ado_about_nothing'.

Arseneault, L., Walsh, E., Trzesniewski, K., Newcombe, R., Caspi, A., \& Moffitt, T. E. (2006). Bullying victimization uniquely contributes to adjustment problems in young children: A nationally representative cohort study. Pediatrics, 118, 130-138.

Bond, L., Carlin, J. B., Thomas, L., Rubin, K., \& Patton, G. (2001). Does bullying cause emotional problems? A prospective study of young teenagers. British Medical Journal, 323, 480-484. 
Boulton, M. J., Trueman, M., \& Flemington, I. (2002). Educational Studies, 28(4), 353-370.

Bjorkqvist, K., Lagerspetz, K. M. J., \& Kaukiainen, A. (1992). Do girls manipulate and boys fight? Developmental trends in regard to direct and indirect aggression. Aggressive Behavior, 18, 117127.

Cadigan, R. J. (2002). Scrubs: An ethnographic study of peer culture and harassment among sixth graders in an urban middle school. Los Angeles, CA: University of California.

Coloroso, B. (2003). The bully, the bullied, and the bystander. New York: HarperCollins Publishers.

Cornell, D. G., \& Brockenbrough, K. (2004). Identification of bullies and victims: A comparison of methods. Journal of School Violence, 3, 63-87. https://doi.org/10.1300/J202v03no2 05

Craig, W. M., Pepler, D., \& Atlas, R. (2000). Observations of bullying in the playground and in the classroom. School Psychology International, 21, 22-36. https://doi.org/10.1177/0143034300211002

Crick, N. R., \& Bigbee, M. A. (1998). Relational and overt forms of peer victimization: A multiinformant approach. Journal of Consulting and Clinical Psychology, 66, 337-347. https://doi.org/10.1037/0022-006x.66.2.337

Dake, J. A., Price, J. H., \& Telljohann, S.K. (2003). The nature and extent of bullying at school. Journal of School Health, 73(5), 173-179.

Emmanuel, O. A., Pamela, Z. T., Michael, L. W., Niina, J., \& Päivi, M. N. (2016). Adolescent loneliness and social anxiety as predictors of bullying victimisation, International Journal of Adolescence and Youth, 21(3), 320-331. https://doi.org/10.1080/02673843.2015.1083449

Frisén, A., Holmqvist, K., \& Oscarsson, D. (2008). 13-year-olds' perception of bullying: Definitions, reasons for victimisation and experience of adults' response. Educational Studies, 34(2), 105-117.

Frisén, A., Jonsson, A. K., \& Persson, C. (2007). Adolescents' perception of bullying: who is the victim? Who is the bully? What can be done to stop bullying? Adolescence, 42(168), 749-762.

Garrett, A. G. (2003). Bullying in American schools. Jefferson: McFarland \& Company, Inc. Publishers.

Glover, D., Gough, G., Johnson, M., \& Cartwright, N. (2000). Bullying in 25 secondary schools: incidence, impact and intervention. Educational Research, 42(2), 141-156.

Gruber, J., \& Fineran, S. (2007). Impact of bullying and sexual harassment on health outcomes of middle school and high school girls. Violence Against Women, 13(2), 627-643. Retrieved from https://pdfs.semanticscholar.org/o8aa/56462747b16a1f33c5114a368fb190ca9oa3.pdf

Hamarus, P., \& Kaikkonen, P. (2008). School bullying as a creator of pupil peer pressure. Educational research, 5O(4), 333-345.

Hawker, D. S., \& Boulton, M. J. (2000). Twenty years' research on peer victimization and psychosocial maladjustment: A meta-analytic review of cross-sectional studies. Journal of Child Psychology and Psychiatry, 41, 441-455.

Hazler, R. J., Hoover, J. H., \& Oliver, R. (1991). Student perceptions of victimization by bullies in school. Journal of Humanistic Education and Development, 29, 143-150.

Hodges, E. V. E., \& Perry, D. G. (1999). Personal and interpersonal antecedents and consequences of victimization by peers. Journal of Personality and Social Psychology, 76, 677-685. https://doi.org/10.1037//0022-3514.76.4.677

Hutchison, E. D. (1999). Dimensions of Human Behavior: The Changing Life Course. Thousand Oaks, CA: Pine Forge Press.

Kim-Cohen, J., Caspi, A., Moffitt, T. E., Harrington, H., Milne, B. J., \& Poulton, R. (2003). Prior juvenile diagnoses in adults with mental disorder: developmental follow-back of a prospectivelongitudinal cohort. Archives of General Psychiatry, 60, 709-717.

Kinderman, P., \& Bentall, R. P. (1996). A new measure of causal locus: the internal, personal and situational attributions questionnaire. Personality and Individual Differences, 20, 261-264. 
M. R. Dangal \& A. R. Singh - Girls Bullying in Nepali Schools: A Perception Study on Awareness...

Kochenderfer, B. J., \& Ladd, G.W. (1996). Peer victimization: cause or consequence of school maladjustment. Child Development, 67, 1305-1317.

La Greca, A. M., \& Lopez, N. (1998). Social anxiety among adolescents: Linkages with peer relations and friendships. Journal of Abnormal Child Psychology, 26, 83-94. https://doi.org/10.1023/A:1022684520514

Lee, C. (2004). Preventing bullying in schools. A guide for teachers and other professionals. London: Paul Chapman Publishing.

Lee, V. E., Croninger, R.G., Linn, E., \& Chen, X. (1996). The culture of sexual harassment in secondary schools. American Educational Research Journal, 33(2), 383-417.

Lund, R., Nielsen, K. K., Hansen, D. H., Kriegbaum, M., Molbo, D., Due, P., \& Christensen, U. (2009). Exposure to bullying at school and depression in adulthood: a study of Danish men born in 1953. European Journal of Public Health, 19, 111-116.

MacDonald, H., \& Swart, E. (2004). The culture of bullying at a primary school. Education as Change, 8(2), 33-55.

Moffitt, TE., E-Risk Study Team (2002b). Teen-aged mothers in contemporary Britain. Journal of Child Psychology and Psychiatry, 43, 727-742.

Molidor, C., \& Tolman, R. M. (1998). Gender and Contextual factors in adolescent dating violence. Violence Against Women, 4, 180-194.

Nansel, T. R., Overpeck, M., Pilla. R.S., Ruan, W. J., Simons-Morton, B., \& Scheidt, P. (2001). Bullying behaviors among US youth: Prevalence and association with psychological adjustment. Journal of the American Medical Association, 285, 2094-2100.

Olweus, D. (1994). Bullying at school: basic facts and effects of a school-based intervention program. Journal of Child Psychology and Psychiatry, 35, 1171-1190.

Olweus, D. (1994). Bullying at school: Basic facts and an effective intervention programme. Promotion \& education, 1(4), 27-31.

Olweus, D. (1993 a). Victimization by peers: antecedents and long-term outcomes. In: K. H. Rubin \& J. B. Asendorpf (Eds.), Social withdrawal, inhibition and shyness in childhood (pp. 315-342). Lawrence Erlbaum Associates: New Jersey.

Olweus, D. (1993b). Bullying at school. What we know and what we can do. Oxford: Blackwell Publishers.

Olweus, D. (1997). Bully/victim problems in school: Facts and intervention. European Journal of Psychology of Education, 12(4), 495.

O'Moore, M., \& Minton, S. J. (2004). Dealing with bullying in schools. A training manual for teachers, parents and other professionals. London: Paul Chapman Publishing.

Prinstein, M. J., Boergers, J., \& Vernberg, E. M. (2001). Overt and relational aggression in adolescents: Social-psychological adjustment of aggressors and victims. Journal of Clinical Child \& Adolescent Psychology, 30, 479-491. https://doi.org/10.1207/S15374424JCCP3004 05

Rana, N. (2006). The experience of being victims of school bullying: A phenomenological study. Unpublished doctoral thesis, Kathmandu University, Kathmandu.

Sharp, S., \& Smith, P. K. (1994). School bullying: Insights and perspectives. Routledge.

Smith, P. K., \& Shu, S. (2000). What good schools can do about bullying: findings from a survey in English schools after a decade of research and action. Childhood, 7, 193-212.

Smith, P. K., \& Morita; Y. (1999). Introduction. The nature of school bullying. A cross-national perspective. London: Routledge.

Sourander, A., Jensen, P., Ronning, JA., Niemela, S., Helenius, H., Sillanmaki, L., Kumpulainen, K., Piha, J., Tamminen, T., Moilanen, I., \& Almqvist, F. (2007a). What is the early adulthood outcome of boys who bully or are bullied in childhood? The Finnish 'From a Boy to a Man' study. Pediatrics, 120, 397-404. 
Sullivan, K., Cleary, M. \& Sullivan, G. (2004). Bullying in secondary schools. London: Paul Chapman Publishing.

Sweeting, H., \& West, P. (2001). Being different: Correlates of the experience of teasing and bullying at age 11. Research Papers in Education, 16(3), 225-246.

Thornberg, R. (2010). Schoolchildren's social representations on bullying causes. Psychology in the Schools, 47(4), 311-327.

Vaillancourt, T., Brittain, H., Bennett, L., Arnocky, S., McDougall, P., Hymel, S., ... \& Cunningham, L. (2010). Places to avoid: Population-based study of student reports of unsafe and high bullying areas at school. Canadian Journal of School Psychology, 25(1), 40-54.

Vaillancourt, T., Hymel, S., \& McDougall, P. (2003). Bullying is power: Implications for school-based intervention strategies. Journal of Applied School Psychology, 19(2), 157-176.

Varjas, K., Meyers, J., Bellmoff, L., Lopp, E., Birckbichler, L., \& Marshall, M. (2008). Missing voices: Fourth through eighth grade urban students' perceptions of bullying. Journal of School Violence, 7(4), 97-118.

Weiss, R. S. (1973). Loneliness. The experience of emotional and social isolation. Cambridge, MA: MIT Press.

Yegidis, B. L., \& Weinback, R. W. (1996). Research methods for social workers. Boston: Allyn and Bacon. 
M. R. Dangal \& A. R. Singh - Girls Bullying in Nepali Schools: A Perception Study on Awareness...

C O A $\mathrm{s}$ 